\title{
PREDICTING MODULUS OF ELASTICITY OF RECYCLED AGGREGATE CONCRETE USING NONLINEAR MATHEMATICAL MODELS
}

\author{
JUNIOR A. REYES-SÁNCHEZ ${ }^{1}$, ANTONIO J. TENZA-ABRIL ${ }^{2}$, FERRAN VERDU $^{3}$ \\ \& JOSÉ A. REYES PERALES ${ }^{3}$ \\ ${ }^{1}$ Department of Civil Engineering, National Autonomous University of Honduras, Honduras. \\ ${ }^{2}$ Department of Civil Engineering, University of Alicante, Spain. \\ ${ }^{3}$ Department of Applied Mathematics, University of Alicante, Spain.
}

\begin{abstract}
It is estimated that currently the consumption of natural aggregates used annually in the production of concrete in the world is around 10 billion tons. Moreover, more than 10 million tons of waste is generated annually from the construction industry. The incorporation of recycled aggregates in the production of concrete arises mainly due to an environmental factor, because it emphasizes the reduction in the consumption of raw materials, reduction of the emission of pollutants to the atmosphere derived from the processes of extraction of natural aggregates, between others. Several studies quantifies the decrease of mechanical properties according to the percentage of replacement of natural aggregate by recycled concrete aggregate. In the present study the authors provide several nonlinear models, which are able to predict the modulus of elasticity behaviour of the concrete manufactured with recycled aggregate. A database was composed of 147 different mixtures of recycled aggregate concrete collected from publications of scientific journals. The database has been used to introduce it to the software Polimodels. Polimodels is able to generate different models using different nonlinear regression algorithms. Six different models for the modulus of elasticity are proposed, dependents on certain physical and mechanical parameters of the recycled aggregate, as the following; the percentage of absorption, Los Angeles abrasion coefficient, and the percentage of substitution of natural aggregate by recycled aggregate. It is possible to appreciate the remarkable reduction in the modulus of elasticity due to the increase of recycled aggregates in the concrete. When the models have more independent variables a better adjustment is noticed that help us to improve the prediction of the modulus of elasticity of recycled aggregate concrete.

Keywords: elastic modulus, nonlinear models, prediction, recycled aggregates, recycled concrete
\end{abstract}

\section{INTRODUCTION}

The use of recycled aggregates (RA) in the production of concrete has many kinds of purposes: the reduction in the consumption of raw materials, the reduction of $\mathrm{CO}_{2}$ emissions into the atmosphere due to natural aggregate (NA) extraction processes, as well as the valorisation of construction and demolition waste $(\mathrm{C} \& \mathrm{~W})$, among others.

It is estimated that the annual consumption in the world of NA used in the production of concrete is about 10 billion tons. In addition, more than 10 million tons of $\mathrm{C} \& \mathrm{~W}$ is generated annually [1]. As a consequence, the environment has to absorb a very important amount of waste materials from the construction sector. Moreover, the construction sector consumes a high quantity of raw materials for the production of concrete.

The use of recycled aggregates concrete (RAC), provides an alternative of high environmental value and more rational from an economic point of view [2]. Extraction of NA, cement manufacturing and all production processes related to the manufacture of concrete, with the consequent energy consumption of these processes, are associated with the emission of tons of $\mathrm{CO}_{2}$ into the atmosphere. For that reason, the use of RA in the manufacture of concrete constitutes a significant step towards a more sustainable society. 
The main difference between the recycled aggregates from concrete (RCA) and the NA is the mortar adhered to the first, which causes a higher water absorption (WA), lower density, higher porosity and a lower wear resistance. Those properties determine the greatest divergence between the two kinds of aggregates. Higher mortar content adhered to the RCA, results in a greater negative effect on the concrete made with it [3]. Usually, RCA has higher roughness, angular shape and porosity and lower density than NA [4].

The use of RCA in concrete production greatly affects the properties of concrete in a fresh state. Workability of concrete decreases with increase of RCA content. This rapid loss of workability is associated with the high absorption of RCA and the increase of fine content during the mixing process as the adhered mortar to the RCA is detached [5]. Currently, the causes of the low utilization of RCA are based on its lower performance against the use of NA $[1,6,7]$. The lower performance in the RCA is mainly due to the higher absorption properties (WA) and higher permeability than in NA [8]. Whit the increase of RCA content in the concrete mixture the modulus of elasticity and compressive strength of RAC decrease [9]. For these reasons, the NA replaced by RCA is limited to a maximum of $20 \%$ in structural concrete by several regulations such as EHE-08 [10].

There are a large number of experimental investigations on RAC that allow the use of the results obtained to describe the behaviour of RAC through mathematical modelling. However, in most of the proposed prediction models, the dependent variable is determined according to the values of the RAC dosage to be produced (w/c ratio, cement quantity, etc.) or mechanical values of the same concrete that is studied (compressive strength, indirect tensile strength or modulus of elasticity). The prediction of the mechanical properties, that can be found several regulations $[10,11]$, implies a high number of experimental measures of the RAC to predict the behaviour.

The main interest of the authors is to predict the modulus of elasticity using several nonlinear mathematical models, knowing some physical properties of the RCA, such as the percentage of water absorption at 24 hours (WA), Los Angeles abrasion coefficient (LA) and percentage of recycled aggregate (RCA). In addition, the modulus of elasticity of a control concrete (concrete with $0 \%$ of RCA in its dosage) will be used as independent variable. Moreover, we pretend to analyze the influence of the number of independent variables in the different proposed nonlinear models.

\section{MATERIALS AND METHODOLOGY}

\subsection{Database}

To achieve the previously mentioned objective, a database has been generated from 147 different mixtures extracted from different researches where the main theme was RCA. The main topic of the selected research is the study of the addition of RCA.

The characteristics of the mixtures used are shown in Table 1. In this table are listed the range of the main materials used in the concrete mixture. As can be seen, the wide range of the dosage will allow the models to be applicable to virtually any type of concrete with recycled aggregate that can be manufactured.

The database reflects the broad spectrum of dosages covered by the study and will greatly influence the mechanical behaviour of the RACs by incorporating RCA [12]. As described above, the study focuses on the treatment of data to generate nonlinear mathematical models, which are able to predict the modulus of elasticity $\left(\mathrm{E}_{\mathrm{RC}}\right)$ of a 28-day-old RAC. First, knowing 
Table 1: Dosage ranges of total analyzed mixtures.

\begin{tabular}{llll}
\hline & $\begin{array}{l}\text { Average value } \\
\left(\mathrm{kg} / \mathrm{m}^{3}\right)\end{array}$ & \multicolumn{2}{l}{ Range of mix proportions $\left(\mathrm{kg} / \mathrm{m}^{3}\right)$} \\
& 364 & Minimum & Maximum \\
\hline Cement content $\left(\mathrm{kg} / \mathrm{m}^{3}\right)$ & 26 & 18 & 520 \\
Addition content $\left(\mathrm{kg} / \mathrm{m}^{3}\right)$ & 0.52 & 0.35 & 35 \\
Water/Cement ratio & 0.52 & 0.35 & 0.82 \\
Water/Binder ratio & 0.46 & 0.24 & 0.82 \\
Effective Water/Cement ratio & 0.48 & 0.29 & 0.72 \\
Effective Water/Binder ratio & 5 & 0 & 0.65 \\
Additive content $\left(\mathrm{kg} / \mathrm{m}^{3}\right)$ & 698 & 395 & 72 \\
Sand $\left(\mathrm{kg} / \mathrm{m}^{3}\right)$ & 531 & 0 & 1000 \\
Gravel $\left(\mathrm{kg} / \mathrm{m}^{3}\right)$ & 543 & 0 & 1353 \\
RCA $\left(\mathrm{kg} / \mathrm{m}^{3}\right)$ & 50 & 0 & 1149 \\
$\%$ RCA $($ in weight $)$ & & & 0.00 \\
\hline
\end{tabular}

some physical properties of the aggregate (WA and LA), the percentage of RAC and the compressive strength of the control concrete without incorporating RAC in its dosage ( $0 \%$ RCA).

To obtain the $\mathrm{E}_{\mathrm{RC}}$ models we have used a database of investigations [1-3, 7, 13-24]. The following phases have been considered; a) knowing the compressive strength value of a concrete with the same RCA degree $\left(f_{c, R C}\right)$ but we still do not know the physical properties of the recycled aggregate (Model 1); after we know the WA value of the RCA (Model 2); and finally we also know the LA value of the RCA (Model 3). b) the $\mathrm{E}_{\mathrm{CC}}$ value of the control concrete is known (Model 4); then, we also know the WA of the RCA (Model 5); and finally the value LA of the RCA (Model 6). It should be noted that WA of the RCA is one of the most important parameters to be taken into account when designing the dosage $[3,10]$ because of WA is greater in RCA than the NA and it will influence the final physical and mechanical properties of the concrete $[12,25]$. As it will be analyzed later in the models and results, most are linked to this parameter.

The main properties of the RA used for the generation of each of the models is shown in Table 2. This Table shows the range of apparent densities of the WA at 24 hours and the LA of the RCA used in the investigations and used for the construction of the models. As can be observed, the wide range of the RAC properties covers the production of any kind of RAC.

The range of the mechanical properties of the RAC used for the different models is shown in Table 3. In this table are listed, for each type of model, the value range and the mean value

Table 2: Physical properties of the aggregates used to generate each of the models.

\begin{tabular}{llll}
\hline & $\begin{array}{l}\text { Average value } \\
\text { Properties of the RCA }\end{array}$ & \multicolumn{2}{l}{ Range of results $\left(\mathrm{kg} / \mathrm{m}^{3}\right)$} \\
\cline { 4 - 5 } \cline { 4 - 4 } Particle density $(\mathrm{kg} / \mathrm{m} 3)$ & 2191 & Minimum & Maximum \\
Water absorption 24 hours $(\%)$ & 5.39 & 1239 & 2750 \\
Los Angeles abrasion coefficient $(\%)$ & 41.26 & 0.24 & 16.34 \\
\hline
\end{tabular}


Table 3: Mechanical properties of the aggregates used to generate each of the models.

\begin{tabular}{llll}
\hline & $\begin{array}{l}\text { Average value } \\
\left(\mathrm{kg} / \mathrm{m}^{3}\right)\end{array}$ & \multicolumn{2}{l}{ Range of results $\left(\mathrm{kg} / \mathrm{m}^{3}\right)$} \\
\cline { 4 - 4 } Mechanical properties of the RCA & 42.7 & 17.3 & Minimum \\
\hline$f_{c}(\mathrm{MPa})$ & 38.3 & 13.4 & 79.0 \\
$f_{c, R C}(\mathrm{MPa})$ & 5.0 & 2.1 & 79.0 \\
$f_{c t, C C}(\mathrm{MPa})$ & 4.3 & 1.4 & 15.5 \\
$f_{c t, R C}(\mathrm{MPa})$ & 32937 & 18900 & 16.5 \\
$E_{C C}(\mathrm{MPa})$ & 28540 & 13800 & 49000 \\
$E_{R C}(\mathrm{MPa})$ & & & 49000 \\
\hline
\end{tabular}

of the compressive strength, tensile strength and modulus of elasticity of the control concretes $(\mathrm{RCA}=0 \%)$ and of the RACs used in the present study. As can be seen the range of values of these properties is wide, so the resulting models will be applicable to a wide range of RAC.

Where $f_{c, R C}$ is compressive strength of the concrete with recycled aggregate substitution (MPa), $f_{c}$ is the compressive strength of the reference concrete without substitution of recycled aggregates (for compressive strength models, MPa), $f_{c t, C C}$ is Indirect tensile strength of the reference concrete $(\mathrm{MPa}), f_{c t, R C}$ is the indirect tensile strength of recycled aggregate concrete $(\mathrm{MPa})$.

\subsection{Nonlinear models}

In general, it is really difficult to find a law that is capable of predicting the mechanical behaviour of concrete, whether or not incorporating recycled aggregate, so that, previously, a study of the dosage of the concrete is done. Subsequently, an experimental campaign is carried out in which the different additions of RA are contemplated and work is carried out with specific modifications of the dosage to achieve the mechanical and durability requirements proposed in the design phase. With these data, although it is true that a prediction law cannot be described, we can make models that can be adjusted and validated adequately from a statistical point of view, which is very useful.

With the problem presented in this way, it is necessary to formally obtain the relation between a variable $y$, dependent on a set of variables $x_{1}, x_{2}, \ldots, x_{n}$, which can be expressed in the relation $y=g\left(x_{1}, x_{2}, \ldots, x_{n},\right)$ where $g$ can be linear or non-linear. The mathematical formulation of the relations obtained from the experimental data is based on the techniques of linear and nonlinear regression analysis. In the case of the former, the most generalized method for obtaining the values of the parameters involved in the equation is the least squares technique, which, by its linearity, leads to the solution of a linear system of the parameters. In contrast, nonlinear regression analysis leads to the use of numerical computation techniques to obtain a solution, the most common methods are Gauss-Newton gradient and Levenberg-Marquardt [25]. Each of these three algorithms poses a series of questions for its computational implementation and concentrate on obtaining the values of the partial derivatives. The procedure becomes cumbersome and also impractical, which makes it essential to use computer programs to facilitate the work, which is why in this study and for practical purposes has been made use of a powerful tool called Polimodels [26,27], 
which use the algorithm with the modules and techniques mentioned above to obtain and validate the parameters, which is considered a hybrid of different computational techniques, numerical calculus and statistical methods.

\subsubsection{Polymodels software}

Polimodels is software that has been implemented using Borland Delphi 6, and therefore is the Pascal object-oriented programming language. The graphical interface is based on menus and windows, and allows the definition of the $\mathrm{MANL}_{\Phi}$, as well as various algorithm parameters and specification criteria previously. This executable generates a result in the form of files [25]. The algorithm that applies is appreciated in Fig. 1 in which basically the GaussNewton algorithm is used to obtain the parameters of the non-linear models.

As described briefly in Section 2.1, the dependent variable analyzed was modulus of elasticity (ERC) of RAC as a function of the independent variables that, depending on the phase, will be 2,3 or 4 .

The ACI 318 [11], EHE-08 [10] and other international regulations provide various formulas to be able to determine the tensile strength and the modulus of elasticity of the concrete, from the compressive strength. In this sense, and as can be seen in the different models, the study was done in the first three cases using as reference parameter the compressive strength of the reference concrete $\left(f_{c, R C}\right)$, with recycled aggregate substitutions. In general terms, the variables that intervene directly in each model are:

$f_{c, R C}$ : Compressive strength of concrete with recycled aggregate substitution (MPa).

$\boldsymbol{E}_{C C}:$ Modulus of elasticity of the reference concrete (MPa).

$\boldsymbol{E}_{R C}$ : Modulus of elasticity of the concrete with percentage of substitution of recycled aggregate calculated from the model (MPa).

$\boldsymbol{R} \boldsymbol{C A}$ : Percentage of recycled aggregate by weight replacing conventional coarse aggregate.

$\boldsymbol{W A}$ : Percentage of water absorption of recycled aggregate at 24 hours.

$\boldsymbol{L A}$ : Los Angeles wear coefficient of the recycled aggregate.

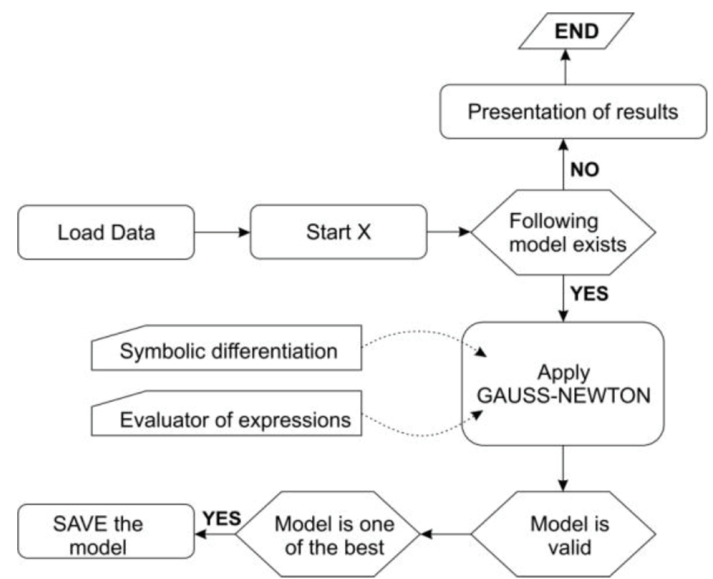

Figure 1: Summary of the process carried out in the research. 
In addition for each of the independent variables we have analyzed the different models that are listed below:
a) $y=E_{R C}\left(f_{c, R C}, R C A\right)$
b) $y=E_{R C}\left(f_{c, R C}, R C A, W A\right)$
c) $y=E_{R C}\left(f_{c, R C}, R C A, W A, L A\right)$
d) $y=E_{R C}\left(E_{C C}, R C A\right)$
e) $y=E_{R C}\left(E_{C C}, R C A, W A\right)$
f) $y=E_{R C}\left(E_{C C}, R C A, W A, L A\right)$

In Table 4 all the variables analyzed in the study are grouped, in addition it is seen how each one of them has been combined to the different 6 generated models. As can be seen for the models there are two possible cases: the first is to know the value of the compressive strength of the concrete with its respective percentage of substitution and the second case is to know a reference parameter, that is, the modulus of elasticity but without substitution of NA by RCA.

\subsubsection{Selection criteria of the generated models}

Having the database completed and also the models that are intended to generate, a debugging is performed. The Polimodels gives us a series of possible models to use; a brief discussion of the different possible selection criteria will be made. We could consider the hypothesiscontrast design as to the advantages of one model over another, but the loss of normality derived from an absence of linearity in many of the resulting models, avoids the calculations of being rigorous and formal. For this reason, any attempt in this sense cannot be more than a mere approximation [26].

First, the value of the coefficient of determination $\mathrm{R}^{2}$ is the most used estimator for regression in the field of research. However, the only consideration of the coefficient of determination as a measure of the goodness of the adjustment leads us to draw the wrong conclusions and the statement that additional measures are needed to complete the analysis [28].

Generally speaking, the model with the lowest average residue must be chosen as the 'best' model to explain the phenomenon [25]. In this sense, several 'distances' can be established

Table 4: Summary table of dependent and independent variables.

\begin{tabular}{|c|c|c|c|c|c|c|c|}
\hline \multirow[b]{2}{*}{ Model } & \multirow{2}{*}{$\begin{array}{l}\text { Parameter } \\
\text { studied }\end{array}$} & \multirow{2}{*}{$\begin{array}{l}\text { Dependent } \\
\text { variable }\end{array}$} & \multicolumn{5}{|c|}{ Independent variables } \\
\hline & & & $f_{c, R C}$ & $E_{C C}$ & $R C A$ & $W A$ & $L A$ \\
\hline 1 & \multirow{6}{*}{$\begin{array}{l}\text { Modulus of } \\
\text { Elasticity for } \\
\text { RAC }\end{array}$} & \multirow{6}{*}{$E_{R C}$} & $\mathrm{x}$ & & $X$ & & \\
\hline 2 & & & $\mathrm{x}$ & & $\mathrm{X}$ & $\mathrm{x}$ & \\
\hline 3 & & & $\mathrm{x}$ & & $X$ & $\mathrm{x}$ & $\mathrm{x}$ \\
\hline 4 & & & & $\mathrm{x}$ & $\mathrm{X}$ & & \\
\hline 5 & & & & $\mathrm{x}$ & $\mathrm{X}$ & $\mathrm{x}$ & \\
\hline 6 & & & & $\mathrm{x}$ & $X$ & $\mathrm{x}$ & $\mathrm{x}$ \\
\hline
\end{tabular}

* 28-day compressive strength, splitting strength and modulus of elasticity. 
between the observed vector and the vector of estimated values; in other words, different rules for the residue vector can be considered, which are defined in eqxs. (1), (2) and (3).

$$
\begin{gathered}
\|e\|=\sqrt{e_{1}^{2}+e_{2}^{2}+e_{3}^{2}+\ldots+e_{k}^{2}} . \\
\|e\|_{1}=\max \left\{a b s\left(e_{1}\right), a b s\left(e_{2}\right), a b s\left(e_{3}\right), \ldots, a b s\left(e_{k}\right)\right\} . \\
\|e\|_{2}=\frac{a b s\left(e_{1}\right)+a b s\left(e_{2}\right)+a b s\left(e_{3}\right)+\ldots+a b s\left(e_{k}\right)}{k} .
\end{gathered}
$$

With $\mathrm{e}_{1}, \ldots, \mathrm{e}_{\mathrm{k}}$ and $\mathrm{k}$ as the absolute value of the difference between the observed value and the estimated value; $k=1$..n. being the number of observations.

It is in this sense that new indexes are sought that incorporate a measure of interpretation more comfortable for the researcher, as is the case of the so-called Mean Absolute Percentage Error (MAPE) for regression models [29], which is defined by eqx. (4).

$$
M A P E=\frac{a b s\left(\frac{e_{1}}{y_{1}}\right)+a b s\left(\frac{e_{2}}{y_{2}}\right)+a b s\left(\frac{e_{3}}{y_{3}}\right)+\ldots a b s\left(\frac{e_{k}}{y_{k}}\right)}{k} .
$$

With $\mathrm{e}_{1}, \ldots, \mathrm{e}_{\mathrm{k}}$ and $\mathrm{k}$ as the absolute value of the difference between the observed value and the estimated value; $\mathrm{y}_{1}, \ldots, \mathrm{y}_{\mathrm{k}}$ are the observed value and $\mathrm{k}=1 . . \mathrm{n}$. is the number of observations.

As can be seen, $e_{k} / y_{k} \cdot 100$ is a measure of the percentage of error committed with respect to our observed variable, $y_{k}$, is in this sense that MAPE is chosen as the measure of discrimination and selection criteria.

\section{RESULTS AND DISCUSSION}

In the results presented below, we can see two parameters that have been crucial choosing the best model. It is provided the value of $\mathrm{R}^{2}$ that although how is explained in detail, is not as representative, has helped us to make inferences as to which model to take but the parameter of choice has been the value of MAPE. Each model has been chosen in such a way that its MAPE is the minimum, as a direct measure that helps us to know how much is the percentage error that is committed between the observed variable and that of the model under study.

\subsection{Models of modulus of elasticity taking as reference parameter $f_{c, R C}$}

Usually, concrete incorporating recycled aggregates has a lower modulus of elasticity than concretes made of conventional aggregates. The modulus of elasticity is related to aggregates and the stiffness of the mortar. According to Bairagi et al. [30] the weakness of the new interfaces between the new mortar and the RAC with the old mortar can cause the development of cracks that affect the deformability of the concrete. This reduction is dependent of the compressive strength of the concrete giving a smaller reduction to higher strengths.

Figure 2 shows the relative modulus of elasticity of the concretes used for the study. The majority of RAC's have a modulus of elasticity lower than its reference (0\% RAC) and only in specific cases exceed the value of the reference concrete. 


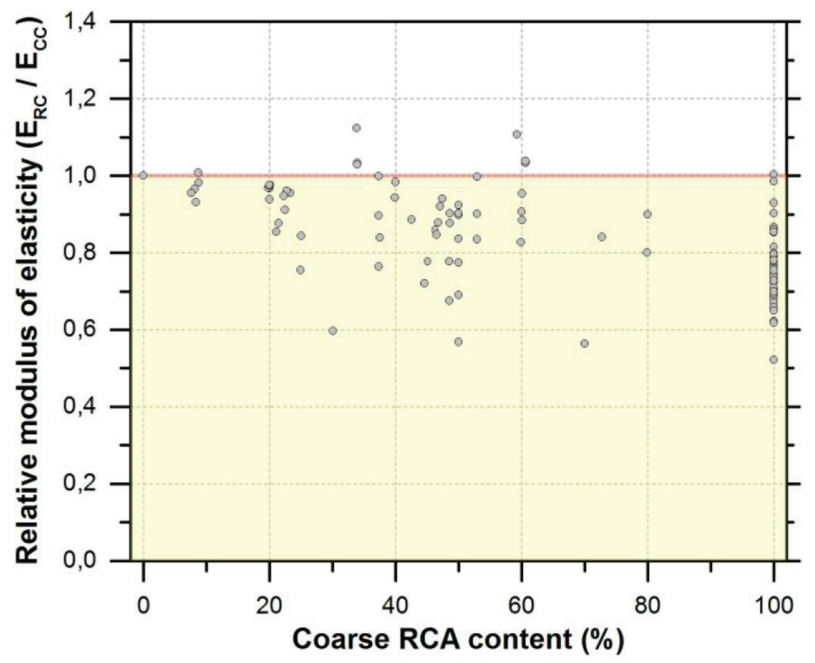

Figure 2: Relative modulus of elasticity of concrete vs coarse RCA content

Models 1, 2 and 3 for $\mathrm{E}_{\mathrm{RC}}$ prediction based on the compressive strength of the RAC with the same percentage of substitution and the properties of the recycled aggregate are described in the following equations.

Model 1: $E_{R C}=\beta_{1} \cdot R C A+\sqrt{\beta_{2} \cdot f_{c, R C}}+\beta_{3}$

Model 2: $E_{R C}=\beta_{1} \cdot W A+\beta_{2} \cdot R C A+\sqrt{\beta_{3} \cdot f_{c, R C}}+\left(\beta_{4} \cdot W A \cdot R C A\right)$

Model 3: $E_{R C}=\sqrt{\beta_{1} \cdot W A}+\beta_{2} \cdot L A^{4}+\beta_{3} \cdot R C A^{4}+\beta_{4} \cdot f_{c, R C}+\left(\beta_{5} \cdot f_{c, R C} \cdot R C A\right)$

Models 4, 5 and 6 for $\mathrm{E}_{\mathrm{RC}}$ prediction as a function of the modulus of elasticity of the reference concrete $\mathrm{E}_{\mathrm{CC}}$, percentage of recycled aggregate replacement and its properties are described in the following equations.

Model 4: $E_{R C}=\beta_{1} \cdot R C A^{2}+\beta_{2} \cdot E_{C C}+\left(\beta_{3} \cdot R C A \cdot E_{C C}\right)$

Model 5: $E_{R C}=\beta_{1} \cdot W A+\beta_{2} \cdot R C A^{2}+\beta_{3} \cdot E_{c, \mathrm{CC}}+\left(\beta_{4} \cdot E_{c, \mathrm{CC}} \cdot R C A\right)$

Model 6: $E_{R C}=\beta_{1} \cdot W A^{3}+\beta_{2} \cdot L A^{4}+\beta_{3} \cdot R C A+\beta_{4} \cdot E_{C C}+\left(\beta_{5} \cdot L A \cdot R C A\right)$

Table 5 shows the coefficients of the different models generated. The data obtained from the literature were compared with the results of the different models. Figure 3 shows the elastic modulus data observed and those calculated using the prediction models described above.

As can be appreciated, the models try to be as simple and clear as possible, so that their application is direct. In Fig. 3 the observed and calculated values are compared and it can be seen the 6 models with their respective MAPE and $\mathrm{R}^{2}$, and their adjustment by adding each one of the variables. How was mentioned previously, the value of MAPE would be taken as the reference parameter because it is a more reliable measure of the correlation between observed and calculated values [28]. In addition, as a complementary measure, the value of $\mathrm{R}^{2}$ is calculated. 
Table 5: Prediction coefficients for models 1, 2, 3, 4, 5 y 6.

\begin{tabular}{lccccc}
\hline Models & $\beta_{1}$ & $\beta_{2}$ & $\beta_{3}$ & $\beta_{4}$ & $\beta_{5}$ \\
\hline Model 1 & $-7.55 \cdot 10^{1}$ & $2.04 \cdot 10^{7}$ & - & - & - \\
Model 2 & $8.05 \cdot 10^{2}$ & $-3.78 \cdot 10^{1}$ & $2.15 \cdot 10^{7}$ & -8.92 & - \\
Model 3 & $6.71 \cdot 10^{7}$ & $-7.45 \cdot 10^{-4}$ & $3.75 \cdot 10^{-5}$ & $4.88 \cdot 10^{2}$ & -3.75 \\
Model 4 & $2.62 \cdot 10^{-1}$ & $9.98 \cdot 10^{-1}$ & $-0.34 \cdot 10^{-3}$ & - & - \\
Model 5 & $-4.68 \cdot 10^{2}$ & $1.51 \cdot 10^{-1}$ & 1.06 & $-2.74 \cdot 10^{-3}$ & - \\
Model 6 & 2.03 & $-3.81 \cdot 10^{-4}$ & $1.25 \cdot 10^{2}$ & 1.00 & -5.84 \\
\hline
\end{tabular}

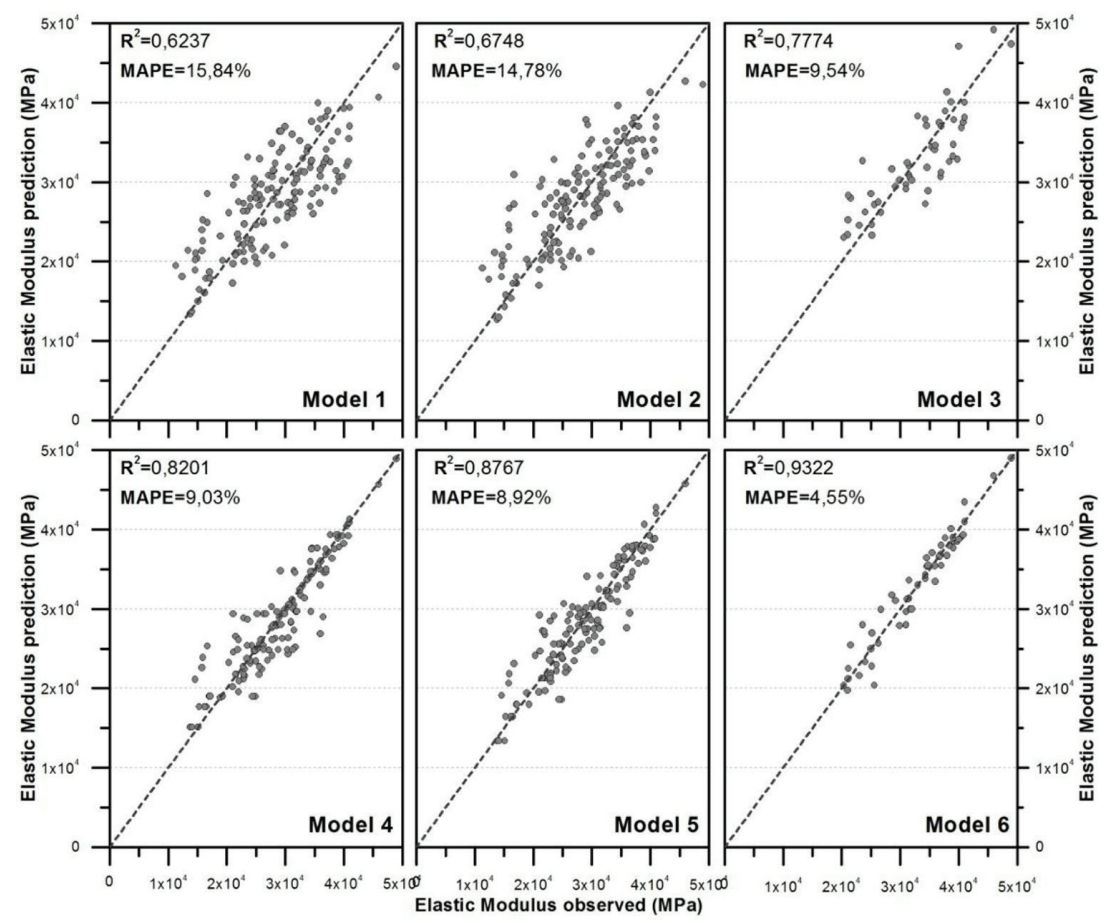

Figure 3: Prediction of calculated values and observed values of modulus of elasticity of the models $1,2,3,4,5$ and 6 .

Figure 4 shows the values of $\mathrm{R}^{2}$ and MAPE for all the different models generated $(1,2$, $3,4,5$ and 6 ) in which, as variables are added to our prediction model. As can be observed there is a decrease in the MAPE values and at the same time an increase in the value of $\mathrm{R}^{2}$. Mainly because $\mathrm{R}^{2}$ and the number of data, usually vary inversely [28] in the same way number of variables also conditions this coefficient since $\mathrm{R}^{2}$ is a non-decreasing function of the number of regressor variables present in the model, so that as the number of variables increases, $\mathrm{R}^{2}$ increases [28]. According to this, $\mathrm{R}^{2}$ measures the explanatory capacity of the different variables $X$, on the variable $Y$, this because introducing another regressive variable in the model, the explanatory level will be greater between the two, than with the first, or in any case, will not diminish because the first variable continues as explanatory. In 


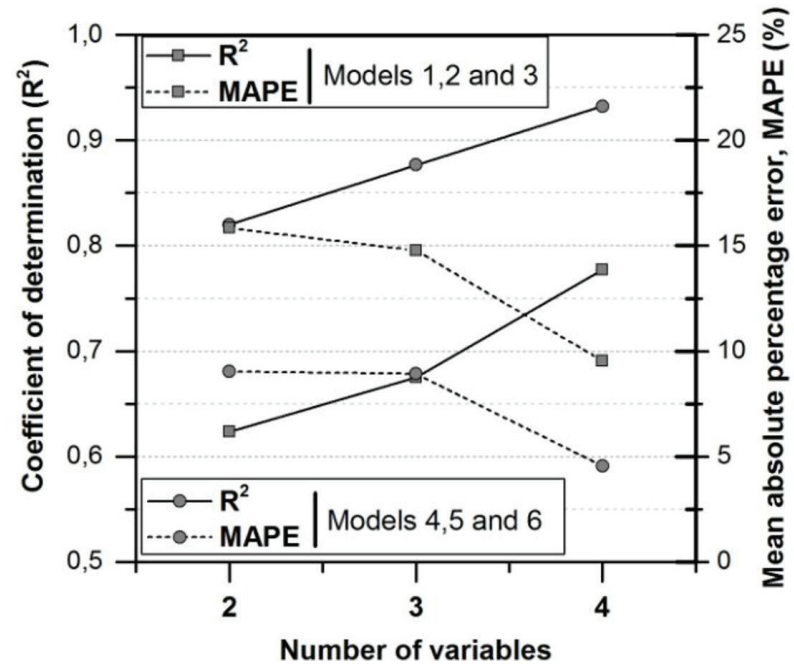

Figure 4: Coefficient of determination $\left(\mathrm{R}^{2}\right)$ and percentage of Mean Absolute Percentage Error (MAPE) as a function of the number of variables for the Modulus of Elasticity prediction models.

addition, it can be appreciated how MAPE decreases as the number of explanatory variables increases.

\section{CONCLUSIONS}

In this paper, the main objective has been to predict the modulus of elasticity of RAC. In order to do this, different studies that cover a wide range of results in the mechanical properties of RAC have been selected in order to obtain nonlinear models that can be adapted to the majority of RAC.

It has been taken into account, not only the percentage of incorporation of recycled aggregate and its physical properties, but also the modulus of elasticity of the reference concrete from which it is intended to replace part of the natural aggregate by recycled aggregate.

The nonlinear models obtained are able to predict the modulus of elasticity of RAC knowing the physical properties of the RCA, the RCA content and knowing the modulus of elasticity of the reference concrete $(0 \%$ RCA). This is an economic saving for the producers since it would not be necessary to manufacture RAC to estimate the value of its modulus of elasticity.

The greater knowledge on the properties of the RCA, such as the WA and LA values, provides nonlinear models with a lower MAPE and a higher value of $\mathrm{R}^{2}$, so we can state that the selection of these variables as explanatory of the modulus of elasticity is completely correct.

These models allow engineers to estimate the modulus of elasticity of recycled concrete as a function of the content of recycled aggregate and the knowledge of the properties of this one (WA and LA).

\section{ACKNOWLEDGEMENTS}

This research was financed by the University of Alicante through projects VIGROB-256 and GRE13-03. Thanks to the National Autonomous University of Honduras for subsidizing studies at the Masters level of one of the researchers at the University of Alicante. 


\section{REFERENCES}

[1] Rahal, K., Mechanical properties of concrete with recycled coarse aggregate. Building and Environment, 42, pp. 407-415, 2007. https://doi.org/10.1016/j.buildenv.2005.07.033

[2] Corinaldesi, V., Mechanical and elastic behaviour of concretes made of recycledconcrete coarse aggregates. Construction and Building Materials, 24, pp. 1616-1620, 2010. https://doi.org/10.1016/j.conbuildmat.2010.02.031

[3] Etxeberria, M., Vazquez, E., Mari, A. \& Barra, M., Influence of amount of recycled coarse aggregates and production process on properties of recycled aggregate concrete. Cement and Concrete Research, 37, pp. 735-742, 2007.

https://doi.org/10.1016/j.cemconres.2007.02.002

[4] Sagoe-Crentsil, K.K., Brown, T. \& Taylor, A.H., Performance of concrete made with commercially produced coarse recycled concrete aggregate. Cement and Concrete Research, 31, pp. 707-712, 2001. https://doi.org/10.1016/s0008-8846(00)00476-2

[5] Safiuddin, M., Alengaram, U.J., Rahman, M.M., Salam, M.A. \& Jumaat, M.Z., Use of recycled concrete aggregate in concrete: a review. Journal of Civil Engineering and Management, 19, pp. 796-810, 2013. https://doi.org/10.3846/13923730.2013.799093

[6] Tabsh, S.W. \& Abdelfatah, A.S., Influence of recycled concrete aggregates on strength properties of concrete. Construction and Building Materials, 23, pp. 1163-1167, 2009. https://doi.org/10.1016/j.conbuildmat.2008.06.007

[7] Rao, M.C., Bhattacharyya, S.K. \& Barai, S.V., Influence of field recycled coarse aggregate on properties of concrete. Materials and Structures, 44, pp. 205-220, 2011. https://doi.org/10.1617/s11527-010-9620-x

[8] McNeil, K. \& Kang, T.H.K., Recycled concrete aggregates: a review. International Journal of Concrete Structures and Materials, 7, pp. 61-69, 2013. https://doi.org/10.1007/s40069-013-0032-5

[9] Topcu, I.B. \& Guncan, N.F., Using waste concrete as aggregate. Cement and Concrete Research, 25, pp. 1385-1390, 1995. https://doi.org/10.1016/0008-8846(95)00131-u

[10] Ministerio de Fomento, EHE-08: Code on structural concrete: Articles and annexes. Ministerio de Fomento, Madrid, 2011.

[11] American Concrete Institute, Building code requirements for structural concrete (ACI 318-08) and commentary, American Concrete Institute, Farmington Hills, Michigan, 2008.

[12] Padmini, A.K., Ramamurthy, K. \& Mathews, M.S., Influence of parent concrete on the properties of recycled aggregate concrete. Construction and Building Materials, 23, pp. 829-836, 2009.

https://doi.org/10.1016/j.conbuildmat.2008.03.006

[13] Barbudo, A., de Brito, J., Evangelista, L., Bravo, M. \& Agrela, F., Influence of waterreducing admixtures on the mechanical performance of recycled concrete. Journal of Cleaner Production, 59, pp. 93-98, 2013. https://doi.org/10.1016/j.jclepro.2013.06.022 
[14] Bravo, M., de Brito, J., Pontes, J. \& Evangelista, L., Mechanical performance of concrete made with aggregates from construction and demolition waste recycling plants. Journal of Cleaner Production, 99, pp. 59-74, 2015. https://doi.org/10.1016/j.jclepro.2015.03.012

[15] Cui, H.Z., Shi, X., Memon, S.A., Xing, F. \& Tang, W., Experimental study on the influence of water absorption of recycled coarse aggregates on properties of the resulting concretes. Journal of Materials in Civil Engineering, 27, pp. 1-9, 2015. https://doi.org/10.1061/(asce)mt.1943-5533.0001086

[16] Gomes, M., de Brito, J. \& Bravo, M., Mechanical performance of structural concrete with the incorporation of coarse recycled concrete and ceramic aggregates. Journal of Materials in Civil Engineering, 26, pp. 1-10, 2014. https://doi.org/10.1061/(asce)mt.1943-5533.0000973

[17] Ismail, S. \& Ramli, M., Mechanical strength and drying shrinkage properties of concrete containing treated coarse recycled concrete aggregates. Construction and Building Materials, 68, pp. 726-739, 2014. https://doi.org/10.1016/j.conbuildmat.2014.06.058

[18] Pepe, M., Toledo, R.D., Koenders, E.A.B. \& Martinelli, E., Alternative processing procedures for recycled aggregates in structural concrete. Construction and Building Materials, 69, pp. 124-132, 2014. https://doi.org/10.1016/j.conbuildmat.2014.06.084

[19] Purushothaman, R., Amirthavalli, R.R. \& Karan, L., Influence of treatment methods on the strength and performance characteristics of recycled aggregate concrete. Journal of Materials in Civil Engineering, 27, pp. 1-7,2015. https://doi.org/10.1061/(asce)mt.1943-5533.0001128

[20] Sheen, Y.N., Wang, H.Y., Juang, Y.P., Le, D.H., Assessment on the engineering properties of ready-mixed concrete using recycled aggregates, Construction and Building Materials, 45, pp. 298-305, 2013. https://doi.org/10.1016/j.conbuildmat.2013.03.072

[21] Xiao, J.Z., Li, J.B. \& Zhang, C., Mechanical properties of recycled aggregate concrete under uniaxial loading. Cement and Concrete Research, 35, pp. 1187-1194, 2005. https://doi.org/10.1016/j.cemconres.2004.09.020

[22] Xuan, D.X., Zhan, B.J., Poon, C.S., Assessment of mechanical properties of concrete incorporating carbonated recycled concrete aggregates. Cement \& Concrete Composites, 65, pp. 67-74, 2016. https://doi.org/10.1016/j.cemconcomp.2015.10.018

[23] Zega, C.J. \& Di Maio, A.A., Recycled concretes made with waste ready-mix concrete as coarse aggregate. Journal of Materials in Civil Engineering, 23, pp. 281-286, 2011. https://doi.org/10.1061/(asce)mt.1943-5533.0000165

[24] Dilbas, H., Simsek, M. \& Cakir, O., An investigation on mechanical and physical properties of recycled aggregate concrete (RAC) with and without silica fume. Construction and Building Materials, 61, pp. 50-59, 2014. https://doi.org/10.1016/j.conbuildmat.2014.02.057

[25] Verdu, F., Un algoritmo para la construcción múltiple de modelos matemáticos no lineales y el estudio de su estabilidad, Thesis, Alicante, pp. 1-617, 2004. 
[26] Verdu, F. \& Villacampa, Y., A computational algorithm for the multiple generation of nonlinear mathematical models and stability study. Advances in Engineering Software, 39, pp. 430-437, 2008. https://doi.org/10.1016/j.advengsoft.2007.03.004

[27] Verdu, F. \& Villacampa, Y., A computer program for a Monte Carlo analysis of sensitivity in equations of environmental modelling obtained from experimental data. Advances in Engineering Software, 33, pp. 351-359, 2002. https://doi.org/10.1016/s0965-9978(02)00023-6

[28] Martínez, E., Errores frecuentes en la interpretación del coeficiente de determinación lineal. Anuario Jurídico y Económico Escurialense, 38, pp. 1133-3677, 2005.

[29] de Myttenaere, A., Golden, B., Le Grand, B. \& Rossi, F., Mean absolute percentage error for regression models. Neurocomputing, 192, pp. 38-48, 2016. https://doi.org/10.1016/j.neucom.2015.12.114

[30] Bairagi, N.K., Ravande, K. \& Pareek, V.K., Behavior of concrete with different proportions of natural and recycled aggregates. Resources Conservation and Recycling, 9, pp. 109-126, 1993.

https://doi.org/10.1016/0921-3449(93)90036-f 